\title{
Toxicity of Vernonia anthelmintica Linn. (Asteracea) seeds against mosquitoes vectors
}

\author{
M . F. Alam ${ }^{1 *}$, A.K . Chopra ${ }^{2}$, M ohammed M . Safhi ${ }^{1}$ and V.K . Dua ${ }^{3}$ \\ ${ }^{1}$ Department of Pharmacology, Faculty of Pharmacy, Jazan University,Jazan, KINGDOM OF SAUDI ARABIA \\ ${ }^{2}$ Department of Zoology and Environmental Science, Gurukula Kangri University, Haridwar, INDIA \\ ${ }^{3}$ National Institute of Malaria Research (ICMR) Field Station, BHEL, Haridwar, INDIA \\ *Corresponding author. E-mail: firoz.a@ rediffmail.com
}

\begin{abstract}
The Toxicological activity (larvicidal, adulticidal and repellent toxicity) of Vernonia anthelmintica seeds fraction was tested against different species of mosquito vectors viz, malaria (Anopheles culicifacies and Anopheles stephensi), filaria (Culex quinquefasciatus) and dengue (Aedes aegypti). The larvicidal toxicity of Vernonia anthelmintica seeds fraction was evaluated against the early $4^{\text {th }}$ instars larvae of different mosquitoes species. Mean $L_{50}$ value of the column fraction KAL-4 from seeds of V. anthelmintica against the larvae of An. culicifacies, An. stephensi, Culex quinquifaciatus and Aedes aegpyti were found to be $64 \mathrm{ppm}, 70 \mathrm{ppm}, 143 \mathrm{ppm}$ and $166 \mathrm{ppm}$ respectively. The larvicidal toxicity was more against An. culicifacies, An. stephensi than Culex quinquifaciatus and Aedes aegypti. The seed extracts did not show any adulticidal toxicity and repellent toxicity even at $10 \%$ concentrated impregnated paper and $5 \%$ on human hand, respectively.
\end{abstract}

Keywords: Toxicogical activity, Vernonia anthelmintica, Mosquitoes

\section{INTRODUCTION}

Mosquitoes are the single largest group of insects, which serve as vectors of several diseases causing various health problems to human beings. Although eradication of these vectors were considered by the use of chemical insecticides, which are now being seriously questioned due to environmental pollution (Edward et al., 1978); multiple resistance (Brown, 1986) and high operational costs. These factors have created the need for environmentally safe, degradable and target specific insecticides against mosquitoes. The search for such compounds has been directed extensively to the plant kingdom. The phytochemicals derived from plant resources can be used as an alternative to the synthetic insecticides (Mittal and Subarao, 2003). A large number of plant extracts have been reported to have mosquitocidal or repellent Toxicity against mosquito vectors (Sukumar et al., 1991). Recently Singh et al., 2002 reported larvicidal properties of leaves extract of Solanum nigrum against Aedes aegypti. Das et al. (2003) reported the evaluation of botanicals as repellents against mosquitoes. While Rajkumar and Jebanesan (2005) reported larvicidal and adult emergence inhibition effects of Centella asiatica Brahmi (Umbelliferae) against mosquito Culex quinquefasciatus and adulticidal Toxicity against An. stephensi. Recently Dua et al. (2008) reported insecticidal activity of Valeriana jatamansi
(Valerianaceae) against mosquitoes.

Verononia anthelmintica (Asteraceae) are annual robust, erect aromatic herbs $(60-90 \mathrm{~cm}$ height) are distributed throughout warm parts of India as a weeds. V. anthelmintica seeds have been used in traditional ayurvedic medicine as anthelmintic, antipyretic and antiinflammatory agents as well as for the treatment of skin diseases such as psoriasis (Kirtkar et al., 1935). The present study was undertaken to investigate the biological Toxicity of different fractions of Vernonia anthelmintica seeds against An. culicifacies, An. stephensi, Culex quinquifaciatus and Aedes aegypti, which could be helpful in mosquito control.

\section{MATERIALS AND METHODS}

Vernonia anthelmintica Lin. (Asteraceae) seeds were procured from local herbal supplier Uttaranchal,(India). The seeds were washed properly, air dried in shade and powdered in Kitchen machine. $100 \mathrm{~g}$ seeds were sequentially extracted using Soxhlet apparatus (6hrs) with petroleum ether, chloroform and methanol, which produced $10 \mathrm{~g}(10 \%)$ petroleum fraction code KAL-a, $1.5 \mathrm{~g}$ (1.5\%) chloroform fraction code KAL-b and $3 \mathrm{~g}$ (3\%) methanol fraction code KAL-c respectively. The crude extracts thus obtained were evaporated to dryness under reduce pressure below $40^{\circ} \mathrm{C}$. Larvicidal, adulticidal and repellent Toxicity of all coded fractions were carried out against different mosquito species in the laboratory of 
Table 1. Percent yield of different extracts from seeds of Vernonia anthelmintica and their larvicidal toxicity against mosquito species.

\begin{tabular}{|c|c|c|c|c|}
\hline \multirow{2}{*}{$\begin{array}{l}\text { Fraction code } \\
\text { (\% Y ield) }\end{array}$} & \multirow[t]{2}{*}{ Solvents } & \multirow[t]{2}{*}{ Mosquito species } & \multicolumn{2}{|c|}{ Toxicity (ppm) } \\
\hline & & & $\mathrm{LC}_{50}^{1}$ (mean $\left.\pm \mathrm{sd}\right)$ & $\mathrm{LC}_{90}($ mean $\pm s d)$ \\
\hline \multirow[t]{4}{*}{ KAL-a (10\%) } & \multirow[t]{4}{*}{ Petroleum ether } & An.culicifacies & $125 \pm 5.0$ & $225 \pm 8.2$ \\
\hline & & An. stephensi & $150 \pm 3.5$ & $230 \pm 9.4$ \\
\hline & & Culex quinquefasciatus & $337 \pm 5.5$ & $456 \pm 4.2$ \\
\hline & & Aedes aegypti & $350 \pm 7.5$ & $595 \pm 8.2$ \\
\hline \multirow[t]{4}{*}{ KAL-b (1.5\%) } & \multirow[t]{4}{*}{ Chloroform } & An. culicifacies & $250 \pm 5.5$ & $440 \pm 4.2$ \\
\hline & & An. stephensi & $275 \pm 4.5$ & $456 \pm 6.5$ \\
\hline & & Culex quinquefasciatus & $612 \pm 6.2$ & $1175 \pm 8.2$ \\
\hline & & Aedes aegypti & $650 \pm 6.2$ & $1050 \pm 7.3$ \\
\hline \multirow[t]{4}{*}{ KAL-c (3\%) } & \multirow[t]{4}{*}{ Methanol } & An. culicifacies & $300 \pm 9.5$ & $550 \pm 5.8$ \\
\hline & & An. stephensi & $350 \pm 7.8$ & $650 \pm 3.5$ \\
\hline & & Culex quinquefasciatus & $625 \pm 12.5$ & $1137 \pm 4.5$ \\
\hline & & Aedes aegypti & $775 \pm 10.0$ & $1237 \pm 3.7$ \\
\hline
\end{tabular}

${ }^{1} \mathrm{LC}_{50}$, median lethal concentration; Number of replicates $=5$

National Institute of Malaria Research, Field Station, Haridwar, India.

Larvicidal toxicity was carried out using all the three fractions mentioned above against early $4^{\text {th }}$ instars larvae of An. culicifacies, An. stephensi, Culex quinquifaciatus and Aedes aegypti as described earlier (WHO, 1996). Twenty larvae of mosquitoes were placed in to $500 \mathrm{ml}$ capacity glass beaker containing $250 \mathrm{ml}$ water. The mosquito larvae were exposed to different concentration of the seed extracts and mixture of dog biscuit and yeast powder in the ratio of 3:2 were provided as nutrients. Mortality of larvae was monitored after $24 \mathrm{hrs}$. Preliminary larvicidal test revealed that petroleum ether fraction (KAL-a) showed good larvicidal toxicity. Hence this fraction was further fractionated in Silica-gel column using petroleum ether; benzene; benzene: chloroform (1:1); chloroform and methanol as mobile phase. Silica gel (60-120m mesh size) was used as stationary phase. The different column fractions were collected and tested against different mosquito's larvae. All tests were carried out in five replicates along with untreated control in the laboratory.

Adulticidal toxicity of different fractions of $V$. anthelmintica seeds were evaluated against $A n$. culicifacies, An. stephensi, Cx. quinquifaciatus and Ae. aegypti. $2.5 \mathrm{ml}$ of each fraction with different concentration viz. $5 \%\left(0.69 \mathrm{mg} / \mathrm{cm}^{2}\right)$ and $10 \%\left(1.38 \mathrm{mg} / \mathrm{cm}^{2}\right)$ were tested on Whatman filter paper (12'15 cm size). Batches of 20 (one day old glucose fed) mosquitoes were exposed on treated papers into WHO susceptibility tube for onehour exposure period and knocked down and then mortality was recorded. After one hour knocked or lived mosquitoes were transferred in the holding tube for further $24 \mathrm{hrs}$ of recovery period and the mortality was recorded. Similarly mosquitoes were exposed in control paper, knocked and then mortality was recoded.

The repellent toxicity of different fractions obtained from the seeds of V. anthelmintica were also carried out on the basis of the protection time against mosquito bites. In the experimental test with repellents only the upper surface of the arm was used, the lower surface was covered with aluminum foil. $0.6 \mathrm{ml}$ of $5 \% \mathrm{v} / \mathrm{v}$ concentration in acetone and coconut oil of each fraction was applied on the upper arm and it was exposed in the mosquito cage (>100 mosquitoes). The number of mosquito bites was counted after every 15 min for 5 min until a confirm bite was received. Similarly, untreated arm was exposed for $5 \mathrm{~min}$. and the rate of mosquitoes biting was recorded. The adult mosquitoes and larvae obtained from wellestablished insectary at National Institute of Malaria Research, Haridwar (Uttranchal), India. All bioassay were performed according to standard methods (WHO, 1996) in the laboratory at constant temperature $26 \pm 2{ }^{\circ} \mathrm{C}$ and relative humidity of $(75 \pm 5) \%$.

\section{RESULTS AND DISCUSSION}

Larvicidal toxicity of isolated fraction code KAL-a, KAL$b$ and KAL-c from seeds of Vernonia anthelmintica was evaluated against mosquito larvae at different concentrations. The $\mathrm{LC}_{50}$ and $\mathrm{LC}_{90}$ values of all three fractions against different mosquito larvae are given in Table 1 . The results revealed that only fraction code KALa was found most effective against mosquito larvae with $\mathrm{LC}_{50}$ range 125-350 ppm. Therefore, further study was confined to isolate the active molecule from KAL-a fraction by column chromatographic methods. The

Table 2. Larvicidal toxicity of different fraction isolated by column chromatography against Anophel es stephensi.

\begin{tabular}{llc}
\hline $\begin{array}{l}\text { Column } \\
\text { fraction }\end{array}$ & Solvents & $\begin{array}{c}\text { Larvicidal toxicity }^{1} \\
\left(\mathrm{LC}_{50} \mathrm{ppm}\right)\end{array}$ \\
\hline KAL-i & Petroleum ether & $>250$ \\
KAL-ii & Benzene & $>250$ \\
KAL-iii & Benzene and & \\
& Chloroform $(1: 1)$ & $>250$ \\
KAL-iv & Chloroform & $71 \pm 8.5$ \\
KAL-v & Methanol & $>250$ \\
\hline
\end{tabular}

${ }^{1}$ Value above $250 \mathrm{ppm}$ was considered no toxicity. 
Table 3. Larvicidal toxicity of fraction KAL-iv against different mosquito larvae.

\begin{tabular}{|c|c|c|c|}
\hline \multirow[t]{2}{*}{ M ost active fraction } & \multirow[t]{2}{*}{ M osquito species } & \multicolumn{2}{|c|}{ Toxicity (ppm) } \\
\hline & & $\begin{array}{c}\mathrm{LC}_{50} \\
(\text { mean } \pm \mathrm{sd})\end{array}$ & $\begin{array}{c}\mathrm{LC}_{90} \\
(\mathrm{mean} \pm \mathrm{sd})\end{array}$ \\
\hline \multirow{4}{*}{ KAL-iv } & An.culicifacies & $64 \pm 10.0$ & $118 \pm 8.0$ \\
\hline & An.stephensi & $71 \pm 8.5$ & $128 \pm 9.0$ \\
\hline & Culex quinquefasciatus & $143 \pm 13.0$ & $260 \pm 12.0$ \\
\hline & Aedes aegypti & $166 \pm 12.0$ & $288 \pm 24.0$ \\
\hline
\end{tabular}

Number of replicates $=4$

bioassay test for larvicidal toxicity of five-column fractions coded as KAL-i (Petroleum ether), KAL-ii (Benzene), KAL-iii (Benzene and Chloroform 1:1), KALiv (Chloroform) and KAL-v (Methanol) were carried out against different species of mosquito larvae are given in Table 2. Among these, fraction code KAL-iv showed good larvicidal Toxicity at $<170 \mathrm{ppm}$ while other fraction did not show any larval mortality even at $250 \mathrm{ppm}$ against different mosquito species within 24 hours. Therefore, further quantitative bioassay of fraction KAL-iv was carried out to find the median lethal concentration. The $\mathrm{LC}_{50}$ and $\mathrm{LC}_{90}$ value of fraction code KAL-iv against different mosquitoes species is given in Table 3. Further purification of the most efficient fraction KAL-iv in to pure compounds using TLC methods did not show any increase of larvicidal Toxicity suggesting that some synergistic factor may play a role regarding the larvicidal Toxicity. Therefore, further study was not carried out to purify the fraction code KAL-iv for insecticidal properties. Results revealed that larvae of Anopheles stephensi $\left(\mathrm{LC}_{50}=64 \pm 10.0 \mathrm{ppm}\right)$ and Anopheles culicifacies $\left(\mathrm{LC}_{50}=71 \pm 8.5 \mathrm{ppm}\right)$ are more susceptible than the larvae of Culex quinquefasciatus $\left(\mathrm{LC}_{50}=143 \pm 13.0 \mathrm{ppm}\right)$ and Aedes aegypti $\left(\mathrm{LC}_{50}=166 \pm 12.0 \mathrm{ppm}\right)$ against the fraction KAL-iv. However, the fraction of $\mathrm{V}$. anthelmintica did not show any adulticidal toxicity and repellent toxicity against mosquitoes.

V. anthelmintica seeds have been used in traditional ayurvedic medicine as an antihelmintic, antipyretic and anti-inflammatory agent as well as treated for skin diseases such as psoriasis (Kirtkar et al., 1935). Pires et al. (2002) reported the Anti-inflammatory toxicity of V. anthelmintica wild seeds extracts. However, there is no report of $\mathrm{V}$. anthelmintica for larvicidal, adulticidal and repellent Toxicity against any mosquito species. The present study showed that seed extracts of $V$. anthelmintica can also be used as a potent larvicide against malaria vectors Anopheles stephensi and Anopheles culicifacies.

The literature indicates that seeds of Syzygium jambolanum (Pushpalatha and Muthukriishnan, 1995), saponin fraction of Agave sisalana (Pizzarro et al., 1999), nine extract of four medicinal plant (Markouk et al., 2000) and pine oil (Ansari et al.,2005) have been suggested for mosquito control.
The larvicidal toxicity of V. anthel mintica is comparable to other well established plant species. In earlier study, Pushpalatha and Muthukriishnan (1995) assessed the partially purified extracts of seeds of Syzygium jambolanum on different instars of Culex quinquefasciatus and Anopheles stephensi and concluded that petroleum ether (PE) : ethyl acetate(EA) in the ratio of $1: 1$ were most active with $\mathrm{LC}_{50}$ value 78.62, 43.87, 194.34 and 228.68ppm against I, II, III and IV ${ }^{\text {th }}$ instars larvae of Culex quinquefasciatus while the $\mathrm{LC}_{50}$ value were 81.53, 84.61, 247.07 and 175.37 ppmagainst I, II, III and IV th instars larvae of Anopheles stephensi. Pizzarro et al. (1999) studied the toxicity of the saponin fraction of Agave sisalana and estimated the $\mathrm{LC}_{50}$ and $\mathrm{LC}_{90}$ value against $3^{\text {rd }}$ instar larvae of Culex quinquefasciatus, that were 183 and 408 ppm, respectively. Markouk et al. (2000) evaluated the 16 extracts of four Moroccan medicinal plants for larvicidal properties against Anopheles labranchiae mosquito larvae and exhibited 9 extracts for high larvicidal toxicity with $\mathrm{LC}_{50}$ values (in the range 28 to $325 \mathrm{ppm}$ ). Recently, Ansari et al. (2005) reported the larvicidal toxicity of pine oil against $A n$. stephensi, $C x$. quinquefasciatus and $A$ e. aegypti with $\mathrm{LC}_{50}$ value 112.6, 85.7 and $82.1 \mathrm{ppm}$, respectively. These concentrations were much higher than those reported in the present study for larvicidal toxicity against malaria vectors. Among different species of mosquitoes the Toxicity of $\mathrm{V}$. anthelmintica was in the order of $64>71>143>166 \mathrm{ppm}$. Besides, the larvicidal toxicity of V. anthelmintica seed fraction KAL-iv is similar to various neem extracts, which are reported to be effective with $\mathrm{LC}_{50}$ values ranging from 55-65 ppm against mosquito larvae (Ascher and Meisner, 1989).

The present study indicates that seeds of V. anthelmintica fraction KAL-iv have potential larvicidal toxicity against malaria vector $A n$. stephenis and An. culicifacies and can help in developing the mosquito larvicidal control agents with reduced environmental impact.

\section{REFERENCES}

Ansari, M. A, Mittal, P. K, Razdan, R.K and Sreehari, U. (2005): Larvicidal and repellent activities of Pine (Pinus longifolia, Family: Pinaceae) oil. J. Vect. Borne. Dis., 42:95-99

Ascher, K.R.S and Meisner, J (1989): The effects of Neem on insect affecting man and animals. In Martin Jacobson, F ocus on phytochemical Pesticide, Vol. I, The neem tree, CRC 
press, Inc., Florida, 113-131

Brown, A.W.A (1986): Insecticide resistance in mosquitoes: a pragmatic review. J. Am. M osq. Cont Assoc., 2:123-140

Das, N. G., Bruah, I., Talukdar, P. K. and Das , S.C (2003): Evaluation of botanicals as repellents against mosquitoes. J. Vector. Born. Dis., 40(1-2):49-53

Dua, V. K., Alam, M. F.,Pandey, A. C., Sawpnil Rai, A. K. Chopra., Kaul, V. K. and Dash A. P. (2008). Insecticidal activity of Valariana J atamansi(Valarianacae) Against mosquitoes. J. Am. M osq. C ont. Assoc., 24(2):315-318

Edwards, C.A, Veresh, G. K. and Ksueger, H. R. (1978). Pesticide residues in the environment in India, U SA Tech. Series No.32, 524

Markouk, M., Bekkouche, K., Larhsini, M., Bousaid, Lazrek, H. B. and Jana, M. (2000). Evaluation of some Moroccan medicinal plant extracts for larvicidal toxicity. J. Ethnopharmacol., 73(1-2): 293-297.

Mittal, P.K. and S.K. Subarao (2003). Prospect of using herbal products in the control of mosquito vectors. ICMR Bull., 33:1-10.

Pizzarro, A. P. B., Oliveira-filho, A. M., Parente J. P, Melo, M.T.V., Santos, C.E and Lima, P. R. (1999). O aproveitamento do residuo da industria do sisal no controle de larvas de mosquitos. Rev. Soc. B ras.M ed. Trop., 32:23-29.

Pires, M., Hout, J. R. S. and Raman, A. (2002). Anti inflammatory toxicity of Vernonina anthel mintica (1.) Willd. seed extracts J. Pharm. Pharmacol., 54.

Pushpalatha, E. and Muthukrishnan, J.(1995). Larvicidal Toxicity of few plant extracts against $C$ ulex quinquefasciatus and A nopheles stephensi. Ind. J ourn. M alariol., 32:14-23.

Rajkumar, S and Jebanesan, A (2005): Larvicidal and adult emergence inhibition effects of Centella asiatica Brahmi (Umbelliferae) against mosquito Cul ex quinquefasciatus Say (Diptera : Culicidae). African J ournal of Biomedical Research, 8(1): 31-33.

Singh, S. P, Raghuvendra and Subarao S. K. (2002). Studies on larvicidal properties of leaf extracts of Solanum nigrum Lnns.(Solanaceae). Curr. Sci.,81:15-29

Sukumar, K., Parich, M. J. and Boobar, C. R. (1991). Botanical derivatives in mosquito control- a review. J. Am. Mosq. Cont. Assoc., 7: 210-287

WHO (1996). Report of the WHO informal consultation on the evaluation and testing of insecticides. CTD/WHOPES/ IC/96.1; 69 